\title{
Life cycle cost and energy conservation for water system pumping station reconstruction
}

\author{
Svetlana Maksimova ${ }^{1, *}$, Anna Shkileva $^{1}$, and Ekaterina Verevkina ${ }^{1}$ \\ ${ }^{1}$ Industrial University of Tyumen, 38, Volodarskogo str., Tyumen 625000, Russia
}

\begin{abstract}
The main goal of this study is evaluation of reconstruction options for water pumping stations, regarding various factors (equipment purchase cost, maintenance, energy consumption). The search for the most profitable solution was carried out using the life cycle cost methodology for the urban water supply system's first lift pump station. An analysis of the operating modes of the pumping station was carried out using curves of pumps and system. It was found that the option with a higher purchase price has the best technological indicators, including energy consumption. The expediency of the complete replacement of pumping equipment is confirmed by an analysis of life cycle costs.
\end{abstract}

\section{Introduction}

According to the forecast of Analytical Center for the Government of the Russian Federation technological energy conservation will become the main direction of reducing energy intensity in housing and communal services for the period until 2040 . This event can give from 25 to $30 \%$ of the total energy saving in the industry.

The introduction of innovative technologies for the consumption of energy resources will lead to a reduction in harmful emissions into the environment and technogenic impact on the climate.

Water supply and sewage system is one of the most energy-intensive sectors in the infrastructure of settlements, second only to the subway in those cities where it is available.

Electricity is the main consumed energy resource. The main amount of electricity is spent on pumping water and supplying air to aeration tanks at wastewater treatment plants.

Energy costs dominate the operating costs of pumping stations in water and wastewater systems $[1,2]$.

According to the Best Available Technologies policy during replacing equipment it is necessary to establish a methodology for assessing the economic and energy efficiency of the reconstruction.

It is necessary to strive for increase in efficiency of resource use at system level for sustainable and economical operation of urban water systems [3].

In the economic analysis of pumping systems, the following methods are used: Net Saving, Saving-to-Investment Ratio SIR, Adjusted Internal Rate of Return (AIRR), Simple Payback (SPB), Discounted Payback (DPB). The main tool to help reduce losses and

\footnotetext{
*Corresponding author: msv020761@yandex.ru
} 
increase energy efficiency of most types of systems, including pumping systems, is life cycle cost analysis. Life cycle costs are calculated over the service life and include the costs of purchase, installation, commissioning, operation, maintenance, and equipment disposal costs. Life cycle cost analysis allows to find the most profitable solution within the scope of available opportunities [4]. Understanding of all the components of the cost of a pumping system is crucial for the correct pump selection in the actual operation condition [5]. Analysis of the life cycle costs for pumping stations provides an important foundation for decision-making as well as offering insights into resource use [6]. Currently, life cycle assessment (LCA) and life cycle cost (LCC) methodologies are widely used to analyze every stage of the water cycle in world cities [3, 7-11]. As the LCA analysis showed, investments in reducing energy consumption at the stage of water abstraction will ensure the environmental sustainability of urban water systems [11]. With global energy and labor costs ahead of the retail price index in much of the developed world low life-cycle cost pump selection is reasonable [12]. Energy conservation in the construction and implementation of projects is a primary goal. The method of assessing energy-saving benefits will optimize economic benefits and energy conservation with a further increase in energy prices [13]. Life cycle cost analysis of the pumps shows that energy cost component is the main cost component of life cycle cost analysis [1]. Therefore, during equipment selection it is necessary to pay attention to energy consumption of pumps and matching with system requirements and pump standard running conditions. Incorrect pump selection, improper matching of pump operating conditions and operation or system requirements are the main causes of lower efficiency $[1,14]$.

\section{Problem}

At water pumping stations in Russian cities equipment, which lifetime expired long ago, is still in use.

When a reconstruction of a pumping station is planned, it is necessary to carry out an inspection of a system, which should include a study of existing operating modes of the system, a monitoring of hydrological regimes of a water supply source.

Based on these data, optimal methods of technological energy saving in the work of water pumping stations should be selected.

For a long time, an approach based on the criterion of minimum reduced costs has been widely used for the economic justification of business decisions in Russian practice. This method has several disadvantages.

The indicator of reduced costs cannot be used for the economic justification of investments allocated for the reconstruction of facilities. In this case, the purchase of better and more expensive equipment is always required. That is initially more expensive than repairing old equipment. In addition, this method doesn't consider the time factor.

When the optimization of total costs is carried out, the ratio between capital (procurement) costs and operating costs should be regulated.

Replacement of pumping equipment should be based on needs of systems and actual conditions, and not mechanically in accordance with existing analogues. For such highly specialized technological equipment as pumps, the search for new methodological approaches is necessary.

\section{Research and results}

\subsection{Pump selection}


Several options for replacing the working pumps of the first lift pump station combined with the water abstraction facility will be considered below.

At present, two centrifugal double-suction pumps manufactured by the Russian company Livgidromash are operating at the station. Technical characteristics of the installed pumps are overstated in terms of head. Two characteristic modes are in the operation of the pumping station: night mode with flow to $4,600 \mathrm{~m}^{3} / \mathrm{h}$, only one pump unit is in operation; daily mode with flow to $8,000 \mathrm{~m}^{3} / \mathrm{h}$, two pump units are in operation.

Based on technological requirements, the operating mode of a first lift pump station with a constant discharge during the day is the most suitable. For the considered station, the average hourly flow in a uniform mode of operation will be equal to $6,600 \mathrm{~m}^{3} / \mathrm{h}$ with a daily output of $158,400 \mathrm{~m}^{3} /$ day.

But there are cases when insufficient deepening of a second lift pump station makes the operation of a first lift pump station in the classical mode with uniform flow impossible. Uneven flow of a first lift pump station negatively affects the operation of water treatment facilities.

Two options for upgrading equipment are developed. In the first version, one pump that is most oversized in head will be replaced. The new pump is LS $800-600-683 \mathrm{~B}$ with impeller diameter $593 \mathrm{~mm}$ and $980 \mathrm{rpm}$. The impeller diameter of the remaining pump 22 NDs will be reduced under the parameters flow $\mathrm{Q}=3,500 \mathrm{~m}^{3} / \mathrm{h}$ and head $\mathrm{H}=45 \mathrm{~m}$.

The second option involves the complete replacement of the working pumps for the parameters: $\mathrm{Q}=6,600 \mathrm{~m}^{3} / \mathrm{h}$ and $\mathrm{H}=42.75 \mathrm{~m}$ with a flow of each pump $3,300 \mathrm{~m}^{3} / \mathrm{h}$. The new pumps are LS 700-500-667D with impeller diameter $600 \mathrm{~mm}$ and $980 \mathrm{rpm}$.

LS type double-entry pumps were selected according to the specified parameters in the Grundfos catalog. The pumps of this type are double suction, single-stage, non-selfpriming, and centrifugal volute pumps.

The pump and system curves of two options are presented in Figures 1 and 2.

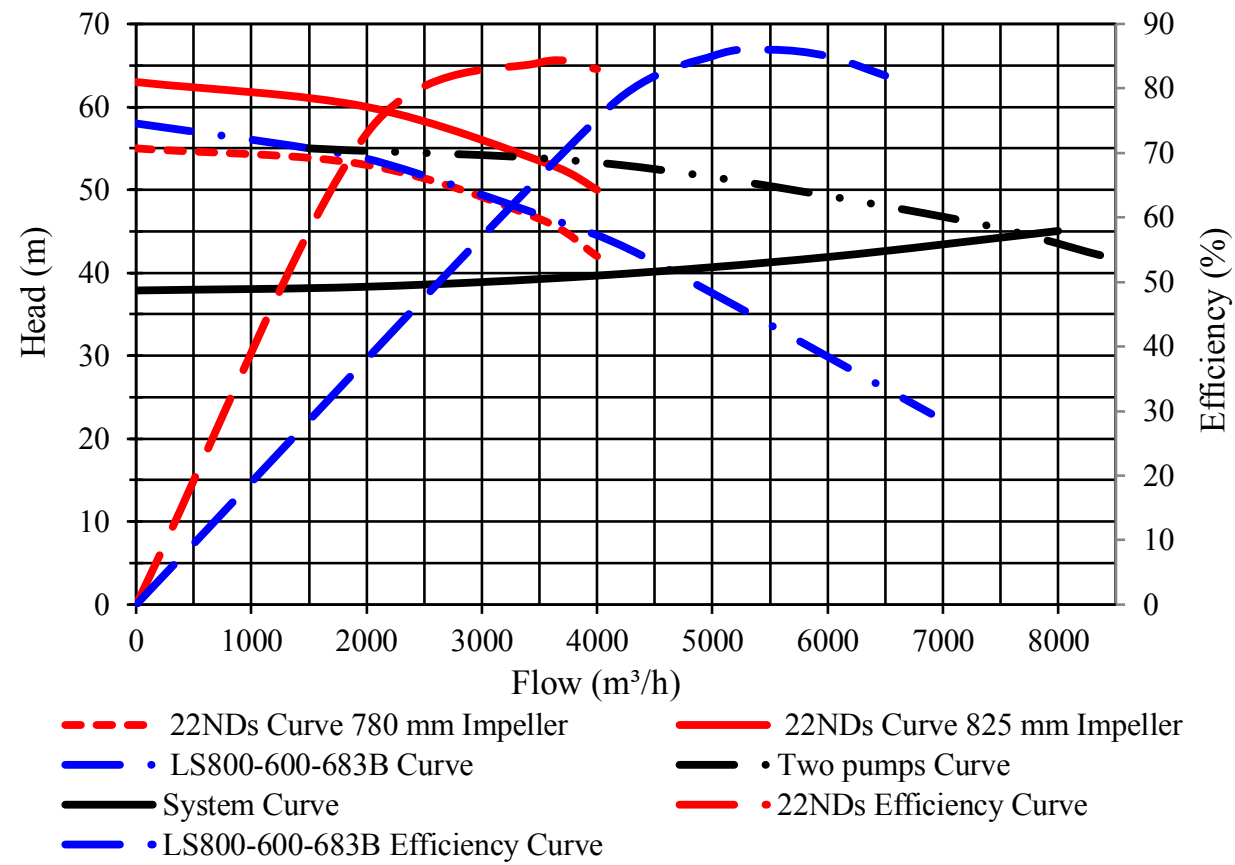

Fig. 1. Pump and system curves of option 1. 


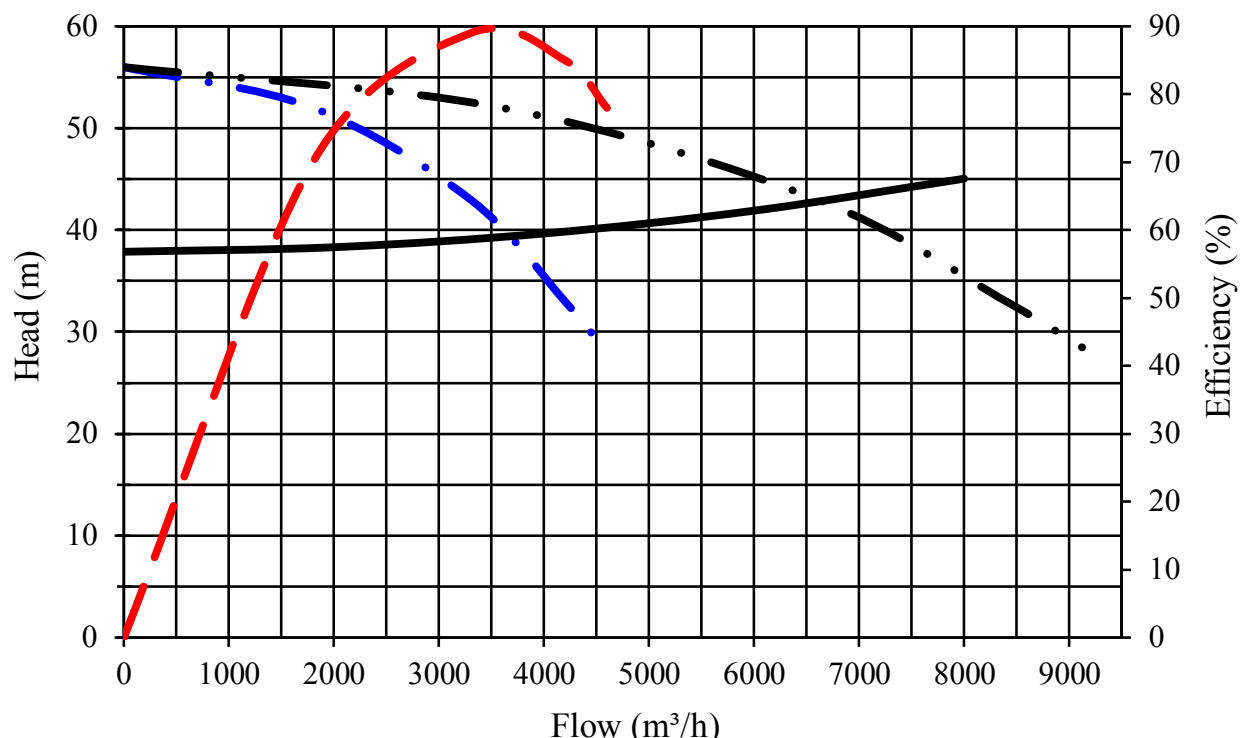

- LS 700-500-667D Curve

System Curve
- Two pumps LS 700-500-667D Curve - Pump Efficiency Curve

Fig. 2. Pump and system curves of option 2.

In the first option, the operating mode of the pumping station will be the same as before the reconstruction, with a flow of $4,600 \mathrm{~m}^{3} / \mathrm{h}$ during the night and a flow of $7,700 \mathrm{~m}^{3} / \mathrm{h}$ during the day. On a day of average water consumption, the new LS 800-600-683B pump will run for 15 hours. Parallel operation of the pumps is expected for 9 hours a day.

In the second option, a single pump operation during the night is expected for 7 hours with a flow of $3,670 \mathrm{~m}^{3} / \mathrm{h}$. In the remaining 17 hours, the pumps operate jointly with a flow of $6,600 \mathrm{~m}^{3} / \mathrm{h}$.

For each upgrade option, the daily energy consumption and specific energy consumption of the pumping station were calculated, and the reduction in energy consumption was determined.

The energy consumption and the specific energy consumption of the pumping station were determined by the formulas:

$$
\begin{gathered}
E=\frac{\rho \cdot g \cdot Q \cdot H}{1000 \cdot \eta} t, k W h \\
E_{\text {spec }}=\frac{E}{Q}, k W h / 1,000 \cdot \mathrm{m}^{3}
\end{gathered}
$$

Where, $\rho=$ density of water, $\mathrm{kg} / \mathrm{m}^{3} ; \mathrm{g}=$ acceleration due to gravity, $\mathrm{m} / \mathrm{s}^{2} ; \mathrm{Q}=$ pump flow, $\mathrm{m}^{3} / \mathrm{s} ; \mathrm{H}$ $=$ pump head, $\mathrm{m} ; \eta=$ efficiency; $\mathrm{t}=$ operating time, $\mathrm{h}$.

The data on equipment modernization options obtained as a result of calculations are shown in Table 1. 
Table 1. Pump station energy consumption.

\begin{tabular}{|c|c|c|c|}
\hline $\begin{array}{c}\text { No. of } \\
\text { reconstruction } \\
\text { option }\end{array}$ & $\begin{array}{c}\text { Pump station energy } \\
\text { consumption, } \\
\mathbf{k W h} / \mathbf{d a y}\end{array}$ & $\begin{array}{c}\text { Specific energy } \\
\text { consumption of the } \\
\text { pumping station, } \\
\mathbf{k W h} / \mathbf{1 , 0 0 0 ~ \mathbf { ~ m }}\end{array}$ & Saving, \% \\
\hline Initial option & 22.919 & 153.56 & - \\
\hline 1 & 20.483 & 147.00 & 10.6 \\
\hline 2 & 18.739 & 134.75 & 18.2 \\
\hline
\end{tabular}

The second option with two new pumps provides the maximum reduction in energy consumption of the pumping station.

Electricity consumption has been identified as one of the main environmental impacts of water supply systems. Therefore, the proposed measures to reduce damage are the basis for ensuring the environmental sustainability of urban water systems [11].

The hourly irregularity coefficient is 1.33 for the first option, 1.15 for the second option. In the second option, the operating mode of the first lift pump station is more uniform.

In this case, favorable conditions for the water purification process are created.

\subsection{Life cycle cost}

Much of a pump initial cost is not in the initial cost of its purchase, but in the energy that it uses over its life [15].

Life cycle cost analysis (LCC) is an effective tool to help identify the most costeffective solution within the scope of available capabilities in water systems.

The LCC elements for each of the compared options are expressed by the equation:

$$
\mathrm{LCC}=\mathrm{C}_{\mathrm{ic}}+\mathrm{C}_{\mathrm{in}}+\mathrm{C}_{\mathrm{e}}+\mathrm{C}_{\mathrm{o}}+\mathrm{C}_{\mathrm{m}}+\mathrm{C}_{\mathrm{s}}+\mathrm{C}_{\mathrm{env}}+\mathrm{C}_{\mathrm{d}}
$$

Where, $C_{i c}=$ initial costs, purchase price (pump, system, pipe, auxiliary services); $C_{i n}=$ installation and commissioning cost (including training); $\mathrm{C}_{\mathrm{e}}=$ energy costs (predicted cost of system operation, including pump driver, controls, and any auxiliary services); $\mathrm{C}_{\mathrm{o}}=$ operation costs (labor cost of normal system supervision); $\mathrm{C}_{\mathrm{m}}=$ maintenance and repair costs (routine and predicted repair); $\mathrm{C}_{\mathrm{s}}=$ down time costs (loss of production); $\mathrm{C}_{\mathrm{env}}=$ environmental costs (contamination from pumped liquid and auxiliary equipment); $\mathrm{C}_{\mathrm{d}}=$ decommissioning / disposal costs (including restoration of the local environment and disposal of auxiliary services) [4].

The life cycle cost formula has a general view, and the user decides which costs will be taken into account in relation to the reconstruction options under consideration.

Direct benefit is the main goal of the method. Therefore, the annual inflation rate should be offset by the interest rate:

$$
C_{n}=C_{p} \cdot[1+(i-\rho)]^{n}
$$

Where, $\mathrm{C}_{\mathrm{n}}=$ upcoming costs in " $\mathrm{n}$ " years; $\mathrm{C}_{\mathrm{p}}=$ current costs; $\mathrm{n}=$ billing period, years; $\mathrm{i}$ $=$ interest rate; $\rho=$ annual inflation rate; $(i-\rho)$ real interest rate share.

The average service life of pumps, according to stated data from manufacturers, is 15 years. According to the Central Bank of the Russian Federation, the key rate is $6.25 \%$, the inflation rate is $3 \%$.

The calculation of the life cycle costs for two options for upgrading the first lift pump station is presented in Table 2 . 
Table 2. Calculation of life cycle costs.

\begin{tabular}{|c|c|c|}
\hline Indicators & First option & Second option \\
\hline \multirow{2}{*}{ Pump type } & LS 800-600-683B & \multirow{2}{*}{ LS 700-500-667D } \\
\hline & 22NDs & \\
\hline \multirow{2}{*}{$\mathrm{Q}, \mathrm{m}^{3} / \mathrm{h}$} & 4,000 & \multirow{2}{*}{3,300} \\
\hline & 3,700 & \\
\hline $\begin{array}{c}\text { Energy consumption of the pump station, kWh per } \\
\text { year }\end{array}$ & $6,454,851$ & $5,613,874$ \\
\hline Initial cost, thousand \$ & 57.151 & 91.095 \\
\hline \multicolumn{3}{|l|}{ Costs, thousand \$. per year: } \\
\hline Energy costs & 510.132 & 443.669 \\
\hline Maintenance costs (scheduled) & 3.801 & 1.901 \\
\hline Repair costs $22 \mathrm{NDs}$ & 1.109 & 0 \\
\hline Total operating costs & 515.04 & 445.57 \\
\hline Service life, years & 15 & 15 \\
\hline Key rate, $\%$ & 6.25 & 6.25 \\
\hline Inflation, $\%$ & 3.0 & 3.0 \\
\hline LCC, thousand \$ & 286.06 & 289.13 \\
\hline
\end{tabular}

Calculations show that a complete replacement of the working pumps (option 2) is most preferable. Despite considerable initial investments, subsequent operating costs save about 70 thousand dollars a year. Given the annual increase in electricity tariffs, the amount of money savings for municipal water/wastewater services will increase.

According to the research, energy carriers' tariff growth and energy-saving potential increasing of the implemented technical solution are main factors, that positively affecting payback period decrease of investments in energy saving [16].

In addition, the difference in the total value of the life cycle costs for the compared options is insignificant, which confirms the advisability of a complete replacement of pumping equipment.

\section{Conclusion}

When the reconstruction options for pumping stations are compared, it is necessary to consider not only the costs of the initial purchase and installation of equipment.

Sometimes an attempt to reanimate old pumps, whose service life has long expired, leads to higher costs for repairs and maintenance than buying new, more advanced equipment. The current mode of operation of the water supply system will be considered when selecting a new pump.

Reasonable replacement of pumps, regarding actual operating conditions of a pumping station, reduces the energy consumption of pumps, which ultimately affects the operating costs and the cost of supplying water. 
Life cycle cost analysis is an effective tool for evaluating the proposed options for the reconstruction of objects of water supply-sewerage services.

\section{References}

1. M.E. Haque, M.R. Islam, M.S. Islam, H. Haniu, M.S. Akhter, Energy Procedia 110, 479-485 (2017) https://doi.org/10.1016/j.egypro.2017.03.172

2. A.A. Shkileva, O.V. Sidorenko, IJCIET 9(5), 589-593 (2018) http://www.iaeme.com/ijciet/issues.asp?JType=IJCIET\&VType=9\&IType=5

3. S. Arden, X. Ma, M. Brown, Water Res. X2, $100012 \quad$ (2019) https://doi.org/10.1016/j.wroa.2018.100012

4. Pump life cycle costs: a guide to the LCC analysis for pumping systems (U.S. Department of Energy, 2001) www.pumps.org

5. P. Noll, World Pumps 2008(496), 32-34 (2008) https://doi.org/10.1016/S02621762(07)70435-2

6. M. Cieslak, World Pumps 2008(505), 30-33 (2008) https://doi.org/10.1016/S02621762(08)70344-4

7. M.J. Amores, M. Meneses, J. Pasqualino, A. Anton, F. Castells, J. Clean. Prod. 43, 8492 (2013) https://doi.org/10.1016/j.jclepro.2012.12.033

8. X. Xue, S. Cashman, A. Gaglione, J. Mosley, L. Weiss, X.C. Ma, J. Cashdollar, J. Garland, Water Res. X2, 100015 (2019) https://doi.org/10.1016/j.wroa.2018.100015

9. M. Zappone, S. Fiore, G. Genon, G. Venkatesh, H. Brattebø, L. Meucci, Procedia Eng. 89, 1382 (2014) https://doi.org/10.1016/j.proeng.2014.11.463

10. V. Marchionni, M. Cabral, C. Amado, D. Covas, Procedia Eng. 119, 168-173 (2015) https://doi.org/10.1016/j.proeng.2015.08.868

11. D. Lemos, A.C. Dias, X. Gabarrell, L. Arroja, J. Clean. Prod. 54, 157-165 (2013) https://doi.org/10.1016/j.jclepro.2013.04.029

12. S. Graham, World Pumps 2007(484), 30-33 (2007) https://doi.org/10.1016/S02621762(06)71209-3

13. W. Li, J. Zhu, Z. Zhu, Energy Procedia 17, 227-232 (2012) doi: 10.1016/j.egypro.2012.02.088

14. E. Larralde, R. Ocampo, World Pumps 2010(2), 24-28 (2010) https://doi.org/10.1016/S0262-1762(10)70029-8

15. J. Tolvanen, World Pumps 2007(490), 34-37 (2007) https://doi.org/10.1016/S02621762(07)70253-5

16. A.S. Gorshkov, N.I. Vatin, P.P. Rymkevich, O.O. Kydrevich, Magazine of Civil Engineering 2, 65-75 (2018) doi: 10.18720/MCE.78.5 